\title{
Some Aspects of Stem Cell Therapy
}

\author{
Sergei Jargin (1) \\ Department of Pathology, Peoples' Friendship University of Russia, Moscow, Russian Federation
}

ORCID iD of the author: S.J. 0000-0003-473I-I853.

Cite this article as: Jargin S. Some aspects of stem cell therapy. Cyprus J Med Sci 2020; 5(2): 183-5.

\begin{abstract}
This short report is an overview of recent literature on stem cells and cell therapies. Certain papers tend to exaggerate positive effects leaving adverse events out of attention. Therefore, conclusions are partly based here on theoretic considerations. There is a discrepancy between the supposed ability of exogenous stem cells to migrate and engraft in tissues, differentiate along various cell lineages, and the absence of clear morphological evidence in vivo. Some papers discuss rejuvenation, replacement of senescent and damaged cells; others explain reported beneficial effects by paracrine or immunomodulating mechanisms. There are no prima facie reasons to assume that paracrine functions are more developed in morphologically primitive SC than in more mature cells. Stem cells are a promising field of research; however, studies of differentiated cells and cell-free products mimicking paracrine effects of cell therapies may be promising as well. Obviously, therapeutic methods with unproven effects should be applied within the framework of sound research shielded from the funding bias.
\end{abstract}

Keywords: Cardiology, cell therapy, myocardium, stem cells

It is evident for a reviewer of scientific literature that the quality of argumentation in some areas of medical research has deteriorated since the last decades. Publication series of questionable reliability have been continued without making references to the published criticism. Another tendency is that drugs and treatments without proven efficiency are advertized and corresponding products marketed as evidence-based medications. Scientific concepts are sometimes construed for this purpose or existing ones used arbitrarily (I-4). The conclusions of this report are partly based on theoretic considerations. In conditions when it is difficult to distinguish between reliable and unreliable papers, theoretic considerations gain in importance. Some questions are not entirely clear, so that arguments provided here can induce a constructive discussion.

Last time, a large number of publications on stem cells (SC) and cell therapies have emerged, some of them containing attractive terms such as rejuvenation, anti-aging strategy etc. (5-7). Discussed topics include the differentiation of exogenous SC into various cell lineages, replacement of senescent, dysfunctional and damaged cells. Remarkably, assumptions that SC can differentiate into specialized cellular elements have not been confirmed for such a perfect SC as the fertilized ovum. In the "experiment" performed by the nature - extrauterine pregnancy - no differentiation of pluripotent embryonic cells towards surrounding tissues is observed but an embryo and germinal layers are formed. The implantation of embryonic SC can result in a development of teratoma $(8,9)$. It is known from general pathology that a focal cell proliferation results in the formation of a nodule rather than migration of individual cells into surrounding tissues. For a pathologist, it is difficult to envisage how SC migrate in tissues such as myocardium, liver or cartilage, arrive at the areas where they are supposed to be needed, and engraft in preexisting structures (IO, II), commented in (I2). The survival and engraftment rates of SC are regarded to be poor (I3).

The migration of SC into ischemic myocardium or infarct zone was reportedly associated with a scar size reduction, cardiomyogenesis and neovascularization (7, 14-17). However, no cardiac SC therapy has been conclusively proven effective (9). Immunohistochemical analyses revealed neither transdifferentiation of mesenchymal SC into cardiomyocytes nor increased vascularization (I5). The participation of SC in myocardial regeneration has been questioned and other mechanisms of the therapeutic action assumed e.g. improved vascularization $(16,18)$. However, the benefit from such vascularization, if it really occurs, is doubtful because ischemia is usually caused by an obstruction of larger epicardial vessels. Accordingly, ischemia can be alleviated by functioning collaterals but not by a locally enhanced microcirculation $(19,20)$. 
As mentioned above, it is difficult to envisage how SC migrate in tissues. In osteoarthritis, SC would have to move through the dense matrix of hyaline cartilage. If even SC after an intra-articular injection are homing in superficial defects of the joint cartilage, synovial or meniscal surfaces (2I), proliferate there and produce extracellular substance, it remains unclear how the smoothness and congruence of joint surfaces is maintained, why the focal cellular proliferation does not result in excrescences crumbling into the articular cavity causing dysfunction and inflammation. Reproducible protocols to induce chondrogenesis by SC are lacking (22). In publications dedicated to the therapy of liver cirrhosis, a differentiation of mesenchymal and other SC to hepatocytes as well as promotion of hepatocyte proliferation is regarded possible $(23,24)$. "The ability of mesenchymal SC to differentiate into hepatocyte-like cells makes them an ideal alternative method for treating liver fibrosis" (25). However, potential differentiation along the mesodermal lineage e.g. to fibroblasts is not discussed. The fibroblastic differentiation would possibly accelerate the advancement of fibrosis and cirrhosis of the liver or other organs. The theoretical basis for the cirrhosis therapy with SC is hardly comprehensible as hepatocytes are capable of mitosis and can hyper-regenerate in cirrhosis whereas nodules are formed.

The action mode of SC remains incompletely described; alternative mechanisms have been proposed: immunomodulating, paracrine (anti-inflammatory, anti-apoptotic, anti-fibrotic, angiogenic, mitogenic), activation of precursor cells in the microenvironment etc. (7,26-28). It was hypothesized that SC secrete anti-aging substances (29). However, there are no prima facie reasons to assume that such special functions would be more developed in morphologically primitive SC or partly differentiated progenitor cells than in more differentiated cells. In any case, experiments with mature cells would be less expensive. The same can be said about cell-free products obtained e.g. from cell culture media and mimicking the paracrine action of cell-based therapies. The latter approach would achieve a better dose standardizing than cell implantations whatever is understood under it (30). Meanwhile, doubts regarding efficiency of cell therapies and concerns about their safety are remaining. Allogeneic transplantations carry the risk of infec-

\section{Main Points:}

- Genetic instability, tumorigenic and immunogenic potential have limited the clinical application of SC.

- There is increasing evidence that a majority of implanted SC do not survive due to the immune rejection and lack of a favorable microenvironment.

- Alternative action mechanisms of SC have been proposed, including paracrine, immunomodulating and trophic. However, there are no reasons to expect more special functions from morphologically primitive SC than from differentiated cells.

- SC are a promising field of research; studies of differentiated cells and cell-free products mimicking paracrine effects of cell-based therapies are promising as well.

- Therapies with unproven effects should be applied within the framework of high-quality research, shielded from bias and to conflicts of interest. tions and immunologic complications (3I). Among others, this is a matter of concern when cell therapies are applied for the treatment of diseases with participation of immune mechanisms. Routes of SC administration or "implantation" include transvenous, transendocardial, intracoronary and transepicardial injections (17, 32-34). In this connection, sources of SC used for intracoronary injections e.g. tissues from induced abortions (32) and their purification from potentially immunogenic components are of importance (35). The infusion of autologous bone marrow cells or fractions of the patient's own blood is sometimes named autotransplantation; it is associated with a lower risk than allotransplantation. However, benefits from such procedures are questionable apart from a restoration of the pool of hemopoietic cells after cytotoxic or immunosuppressive treatments (e.g. of hematological malignancies or multiple sclerosis) or similar applications that have been known long since.

All said, SC seem to be a promising field of research. However, studies of differentiated cells and cell-free products mimicking paracrine effects of cell-based therapies may be promising as well. Unfortunately, the literature is partly biased, exaggerating positive effects, if there are any. Some patients pay for cell therapies; but the experience is partly lost for the science because some conflicted researchers overestimate positive results leaving adverse effects out of attention. One of the objections to prohibitive measures $(36,37)$ is that the hope is taken from severely ill patients. Obviously, therapeutic methods with unproven effects must be applied within the framework of sound research shielded from the funding bias. Patients participating in such research should be treated free of charge.

Peer-review: Externally peer-reviewed.

Conflict of Interest: Authors have no conflicts of interest to declare.

Financial Disclosure: The authors declared that this study has received no financial support.

\section{REFERENCES}

I. Jargin SV. Drugs and dietary supplements with unproven effects in research and practice. J Complement Med Res 2019; IO(I): 27-7. [Crossref]

2. Jargin SV. Hormesis: Umbrella mechanism only for agents present in the environment. Hum Exp Toxicol 2015; 34(4): 439-4l. [Crossref]

3. Jargin SV. Development of antiatherosclerotic drugs on the basis of cell models: A comment. Int J Pharmacol Phytochem Ethnomed 2015; I: 10-14. [Crossref]

4. Jargin SV. Glycosaminoglycans and their precursors in osteoarthritis. Open Veterinary Journal 2018. Available From: URL: https:// www.openveterinaryjournal.com/OVJ-Letter-7-I-20I8-S.V.\%20 Jargin.pdf

5. Lau A, Kennedy BK, Kirkland JL, Tullius SG. Mixing old and young: enhancing rejuvenation and accelerating aging. J Clin Invest 2019; 129(I): 4-II. [Crossref]

6. Nguyen N, Sussman MA. Rejuvenating the senescent heart. Curr Opin Cardiol 2015; 30(3): 235-9. [Crossref]

7. Neves J, Sousa-Victor P, Jasper H. Rejuvenating strategies for stem cell-based therapies in aging. Cell Stem Cell 2017; 20(2): 161-75. [Crossref]

8. Blum B, Benvenisty N. The tumorigenicity of diploid and aneuploid human pluripotent stem cells. Cell Cycle 2009; 8(23): 3822-30. [Crossref] 
9. Lin FC, Chen WP, Chu PH, Shyu KG, Wen MS. Current status and perspectives in stem cell therapy for heart. Acta Cardiol Sin 2014; 30(5): 382-94.

10. Jargin SV. Stem cells and cell therapy. Cardiology 20I0; II7(3): 198. [Crossref]

II. Jargin SV. Stem cells and cell therapy: on the eve of scientific discovery. Cell Tissue Biol 20ll; 5: 103-5. [Crossref]

12. ter Horst K.W. Stem cells and cell Therapy: popular belief? Cardiology 2010; II7(3): 199. [Crossref]

13. Tang JN, Cores J, Huang K, Cui XL, Luo L, Zhang JY, et al. Concise Review: Is Cardiac Cell Therapy Dead? Embarrassing Trial Outcomes and New Directions for the Future. Stem Cells Transl Med 2018; 7(4): 354-9. [Crossref]

14. Elnakish MT, Hassan F, Dakhlallah D, Marsh CB, Alhaider IA, Khan M. Mesenchymal stem cells for cardiac regeneration: translation to bedside reality. Stem Cells Int 2012; 2012: 646038. [Crossref]

15. Jaquet K, Krause KT, Denschel J, Faessler P, Naverz M, Geidel S, et al. Reduction of myocardial scar size after implantation of mesenchymal stem cells in rats: what is the mechanism? Stem Cells Dev 2005; 14(3): 299-309. [Crossref]

16. Le T, Chong J. Cardiac progenitor cells for heart repair. Cell Death Discov 2016; 2: 16052. [Crossref]

17. Suncion VY, Ghersin E, Fishman JE, Zambrano JP, Karantalis $V$, Mandel $N$, et al. Does transendocardial injection of mesenchymal stem cells improve myocardial function locally or globally? An analysis from the Percutaneous Stem Cell Injection Delivery Effects on Neomyogenesis (POSEIDON) randomized trial. Circ Res 2014; II4(8): 1292-30I. [Crossref]

18. Martin-Rendon E, Brunskill SJ, Hyde CJ, Stanworth SJ, Mathur A, Watt SM. Autologous bone marrow stem cells to treat acute myocardial infarction: a systematic review. Eur Heart J 2008; 29(I5): |807-I8. [Crossref]

19. Nagy JA, Dvorak AM, Dvorak HF. VEGF-A(I64/165) and PIGF: roles in angiogenesis and arteriogenesis. Trends Cardiovasc Med 2003; 13(5): 169-75. [Crossref]

20. Schaper W, Buschmann I. VEGF and therapeutic opportunities in cardiovascular diseases. Curr Opin Biotechnol 1999; 10(6): 54I-3. [Crossref]

21. Wyles CC, Houdek MT, Behfar A, Sierra RJ. Mesenchymal stem cell therapy for osteoarthritis: current perspectives. Stem Cells Cloning 2015; 8: II7-24. [Crossref]

22. Castro-Viñuelas R, Sanjurjo-Rodríguez $C$, Piñeiro-Ramil M, Hermida-Gómez T, Fuentes-Boquete IM, de Toro-Santos FJ, et al. Induced pluripotent stem cells for cartilage repair: current status and future perspectives. Eur Cell Mater 2018; 36: 96-109. [Crossref]

23. Berardis S, Dwisthi Sattwika P, Najimi M, Sokal EM. Use of mesenchymal stem cells to treat liver fibrosis: current situation and future prospects. World J Gastroenterol 20I5; 2I(3): 742-58. [Crossref]

24. Kwak KA, Cho HJ, Yang JY, Park YS. Current perspectives regarding stem cell-based therapy for liver cirrhosis. Can J Gastroenterol Hepatol 2018; 2018: 4197857. [Crossref]

25. Guo Y, Chen B, Chen LJ, Zhang CF, Xiang C. Current status and future prospects of mesenchymal stem cell therapy for liver fibrosis. $J$ Zhejiang Univ Sci B 2016; 17(II): 83I-4I. [Crossref]

26. Comella K, Parcero J, Bansal H, Perez J, Lopez J, Agrawal A, et al. Effects of the intramyocardial implantation of stromal vascular fraction in patients with chronic ischemic cardiomyopathy. J Transl Med 2016; 14(I): 158. [Crossref]

27. van den Akker F, de Jager SC, Sluijter JP. Mesenchymal stem cell therapy for cardiac inflammation: immunomodulatory properties and the influence of toll-like receptors. Mediators Inflamm 2013; 2013: 181020. [Crossref]

28. Jeong H, Yim HW, Park HJ, Cho Y, Hong H, Kim NJ, et al. Mesenchymal stem cell therapy for ischemic heart disease: systematic review and meta-analysis. Int J Stem Cells 20I8; II(I): I-I2. [Crossref]

29. Ullah M, Sun Z. Stem cells and anti-aging genes: double-edged sworddo the same job of life extension. Stem Cell Res Ther 2018; 9: 3. [Crossref]

30. Terzic A, Behfar A. Posology for regenerative therapy. Circ Res 2017; I2I(II): |2|3-5. [Crossref]

31. Tasso R, Pennesi G. When stem cells meet immunoregulation. Int Immunopharmacol 2009; 9(5): 596-8. [Crossref]

32. Kirillov AM, Fatkhudinov TKh, Dyachkov AV, Koroteev AV, Goldshtein DV, Bochkov NP. Transplantation of allogenic cells in the therapy of patients with dilated cardiomyopathy. Bull Exp Biol Med. 2007; 144(4): 635-9. [Crossref]

33. Schoenhard JA, Hatzopoulos AK. Stem cell therapy: pieces of the puzzle. J Cardiovasc Transl Res 2010; 3(I): 49-60. [Crossref]

34. Bilgimol JC, Ragupathi S, Vengadassalapathy L, Senthil NS, Selvakumar K, Ganesan M, et al. Stem cells: An eventual treatment option for heart diseases. World J Stem Cells 2015; 7(8): III8-26. [Crossref]

35. Jargin SV. Scientific misconduct and related topics. Am J Exp Clin Res 2017; 4(I): 197-20I.

36. Rossbaver M. Unproven stem-cell therapy ban. Nature 2008; 454(7207): 923. [Crossref]

37. Qiu J. China clamps down on controversial therapies. Lancet 2009; 373(9678): 1834-5. [Crossref] 